\title{
The Strategies for Using ICT in Smartization of Schools: A Qualitative Study on a Group of Experts
}

\author{
Jamal Salimi, ${ }^{1}$ Ghobad Ramezani, ${ }^{2, *}$ and Mohammad Asadi ${ }^{3}$ \\ ${ }^{1}$ Curriculum Planning, Department of Educational Sciences, University of Kurdistan, IR Iran \\ ${ }^{2}$ Educational Planning from Department of Educational Sciences Department of Educational Sciences, University of Kurdistan, IR Iran \\ ${ }^{3} \mathrm{PhD}$ Student in Higher Education Development Planning, Department of Educational Sciences, University of Kurdistan, IR Iran \\ "Corresponding author: Ghobad Ramezani, Educational Planning from Department of Educational Sciences Department of Educational Sciences, University of Kurdistan, IR \\ Iran. E-mail: ramazanighobad@gmail.com
}

Received 2017 February 26; Accepted 2017 February 27.

\begin{abstract}
Context: The present era of information and communication technology have affected various aspects of individual and social life. In smart schools, information and communication technologies are accompanied with a comprehensive and holistic model, entering predetermined goals and missions into the field of education. The present study aimed at exploring the challenges and strategies in the use of ICT to smartize schools.

Methods: A qualitative approach was adopted in the present study in conducting interviews with 3 focus group experts (faculty members, teachers, and specialists in educational technology) in the city of Sanandaj. Semi-structured interview was used for data collection. Criterion-based purposive sampling method was used to study the experts 'viewpoints ( 4 faculty members, 7 experienced teachers, and 4 experts of information and communication technology in education). In addition, thematic content analysis was used to encode data and summarize the interviews. Finally, strategies were developed using the environmental analysis of SWOT.

Results: The findings suggested that smartization of schools have noteworthy strengths. These strengths are as follow: encouraging active learners, developing the identity of students, offering opportunities for interactive learning in educational settings, and promoting qualitative development of education. The weaknesses of school smartization process were insufficiency of specialized human resources, incorrect culture in use of ICT tools, and certain challenges (weakness in policymaking, ICT development strategies, and disruption of structural and infrastructure-related factors.

Conclusions: Fundamental contributive steps could be taken by minimizing weaknesses and challenges, maximizing strengths and opportunities for smart schools, and adopting appropriate strategies for smart schools by experts.
\end{abstract}

Keywords: Smartization of Schools, Instructional Technology, Strategies and Challenges, SWOT Model, Experts Group

\section{Context}

One of the areas revolutionized by introduction of information technology is education. Today, use of modern technologies in learning and teaching processes is a necessity because developing these technologies contributes to conversion of knowledge in a practical way. In this regard, one of the proper strategies is to establish smart schools. Numerous evolutions and changes have occurred in different fields, the majority of which are rooted in the development of information and communication technology. ICT have contributed to numerous changes in cultural, economic, and political fields. Educational system is not an exception to these global changes and developments (1). Initially, globalization was not an educational issue, but it primarily was an economic concern. Regardless of incentives, globalization covers every field and due to the mutual dependence and association of cultural, political, and economic factors with education, any evolution in abovementioned fields could revolutionize the educational sys- tem (2). To ensure the coordination of educational system of each country with global development, the educational system should align itself with evolutions of the modern society, predict future visions and events, and develop desirable outcomes in the future. One may consider smartization of schools as the most suitable model for developing information and communication technology in education. Smart schools refer to a group of educational units that adopt e-learning methods, maintain physical setting of schools, provide face-to-face interaction between teachers and students, and use smart educational system and integrated approach to offer optimal educational services to students. These schools are aimed at developing a logical and suitable structure for integration of ICT and content of lessons in a smart manner so that ICT is recognized as foundation of learning.

Previous studies suggest that ICT plays a key role in development plans of countries. Thus, development of ICT is not only a choice, but a necessity for modification of educational systems. To satisfy new requirements of the society, 
smart schools were established, offering learning-training environment and improved management systems. Smart schools are one of the achievements of ICT development, which aim to revolutionize the educational system in an informed and targeted manner or improve the current system. For the first time, David Perkins et al. in Harvard University introduced smart schools design as a new experience in enforcement of educational programs through ICT (3). Smart school is regarded as an educational system in which all processes such as management, monitoring, control and learning (ie, learning educational sources, review of documents and administrative affairs, communications and principles of developing them) are premised on information and communication to improve the existing research-based educational systems (4). In smart schools, technology acts as a facilitating and enabling factor as it not only satisfies current educational objectives but also offers a labor force that could face existing challenges. If proper attempts are made for the proper use of information to realize the development plan, the educational system could establish smart schools, act as the largest source of skilled labor force skilled in information technology, and play a significant scientific and economic role in the country and the world. Thus, establishing smart schools could contribute to harmonizing with environmental changes and using modern technologies. Progress of the educational system necessitates proper use of its capacities.

Despite undeniable advantages of smart schools in evolution of educational system, enforcement of this plan has always faced certain limitations and problems. Insufficiency of skilled labor force and financial and physical resources for equipping smart schools with computer systems and other necessary tools are among common problems of developing such schools. Results of other studies suggest that a significant problem of the existing organizational structures in educational systems is culture and ability of using the offered means, environmental conditions, and perception of general thoughts on this phenomenon. For instance, lack of proper culture of using information causes serious problems for the public and authorities as well as teachers in promoting and developing smart schools (5).

Abdolvahabi et al. conducted a survey titled, "Feasibility of Establishing Smart Schools in High Schools of Ahvaz". They concluded that managers and administrators perceived the readiness of high schools to shift to smart schools to be low (6).

Mohajerani et al. conducted a study titled, "Main Reasons Behind Malfunction of Smart Schools and Offering Solutions for Their Development in Mazandaran Province". The results suggested that provincial schools have desir- able satisfying standards for conceptual model of smart schools. However, lack of essential infrastructures and insufficiency of financial resources for developing proper hardware equipment were among the major obstacles for establishing smart schools. Moreover, it was found that preparedness of smart schools was dependent on development of information and communication infrastructure. Development of smart schools in Mazandaran province was resuming, but there were numerous challenges and problems against implementation of this plan, which should be addressed through precise planning and expending sufficient time and funds. In such a case, conditions for quick development of these schools should be considered (3).

Alizade conducted a study on the qualitative review of education in smart schools of Tehran. The results suggested that quality of objectives, management, and organizational position of schools were all desirable except for one school. However, quality of teachers was in a relatively favorable level. In addition, students' use of information technology was relatively desirable. Except for one school, the fourth factor (educational programs for enhancing teachers' knowledge) was judged to be at a favorable level. Except for one school, the fifth factor (ie, learning-training process) needed further improvement in all schools. Finally, quality of sixth factor (ie, physical equipment and resources) was at a desirable level (except for one school). In this regard, one could state that two thirds of the studied schools needed to enhance the quality of their current methods to attain a proper status (7).

A study was conducted by Zaman et al. titled, "The Study of Use of ICT for Creating Learning Opportunities by Administers of Smart Schools Located in Tehran". Their results suggested that condition of using ICT in smart schools for creating learning opportunities (by teachers) was at a moderate level. In addition, use of ICT was at a low level, but the status of teachers in creating good learning opportunities was good (8).

Afzal Khani and Qods conducted a study titled, "Evaluation of Status of Establishment of Smart High Schools in Semnan Province from Viewpoints of Administrators and Lecturers". The results suggested that schools required more endeavors in administration of school through integrated computer system, learning and training system, infrastructure for developing information technology, and integrated computer-based associations with other smart schools to establish a uniform system of smart schools in the province. The results suggested that teachers who had received training on integrated administration and technology showed proper potential for establishing smart schools (9).

Some other studies conducted on this issue (quoted 
from Yazdani, 2011) pointed to several barriers against development of smart schools, which are as follow: insufficient number of computers, insufficient skills and knowledge of teachers, problems of integrating technology and education, lack of technical and monitoring experts, high costs and low hardware and software means, lack of relevant applications with online access, lack of training, insufficient time and pressure of curriculum, limited access, problem of matching with new educational roles, insufficient financial resources for implementing information technology in educational domain, insufficient trained labor force, unclear objectives in using computers for education, low motivation due to insufficient training of teachers and students, lack of familiarity with English and lack of fluency in English, and lack of a valid scientific model (10).

Jafari Hajati conducted a survey entitled, "Evaluation of School Smartization Plan in High Schools of Tehran: A Case Study of Absal High school". They concluded that use of information technology could, as a medium, change foundation and structure of learning. This is solely possible through changes in roles of students and teachers as well as structural modification of educational content. In their survey, realization of objectives of smart schools in Absal high school was evaluated by teachers at a moderate level, while students evaluated realization of such an objective to be high. In addition, the 2 groups of teachers and students evaluated financial and human-related problems at high levels (11).

Ibrahim et al. (Quoted from Hedari et al. 2014) conducted a descriptive-analytic study titled, "Principles of Smartization and Smart Schools in Malaysia”. Most school administrators were not prepared enough to implement the smartization system. In addition, and the role of the government in supporting the system was emphasized. Before the year 2020, all Malaysian schools should be equipped with smartization system. For more effective learning, learners should adopt common education methods and internalize these items in their educational system and develop their infrastructures in every aspect (12).

Hamid published a paper (Teachers' Beliefs and Use of ICT in Smart Schools of Malaysia) to discuss the way they used ICT in their classroom. The results suggested that although managers viewed ICT positively in education, they did not use it in their classrooms. Most of them believed that ICT is solely a tool used for training and learning and should be used if it could facilitate communication of knowledge and understanding of content by students (13).

Salimi and Qanodi conducted a survey titled, "Study and Comparison of Curriculum in Smart and Traditional Schools" and compared level of students' learning through new teaching methods (use of technology) and traditional teaching method. They concluded that fundamental changes of infrastructures and teaching methods are needed in the new era of education. In addition, elements of curriculum should align with technological changes. They stated that both learners and teachers favor this new system despite executive problems. This method could help students develop creative solutions and improve their learning. Because each learner acts based on his/her abilities, individual differences should be considered in this method (14).

Considering the challenges against smartization of schools, the present study was done qualitatively. Based on SWOT model, the viewpoints of those experts participating in this study were obtained, proper solutions extracted, and solutions developed to address the problems and take steps towards a more effective training and learning. Therefore, the primary objective of the present study was to review the challenges and strategies in using ICT in school smartization process. Based on the questions raised during the reviews, the following question was inferred from the thematic analysis of the data:

Q.1- What strategies are suggested for use of ICT in smartization process?

\section{Methods}

This was a qualitative study, with interviews, and 3 focus groups (4 faculty members, 7 experienced teachers, and 4 educational ICT experts), who were living in Sanandaj. The criterion for selecting participants was sufficient knowledge and expertise on school smartization. Interviewing these individuals set the theoretical saturation for reaching a sufficient sample size. The instrument used for data collection was semi-structured interview. Criterionbased sampling was used to facilitate clarification of approaches of the experts. In addition, thematic analysis method was used to code the data and summarize the interviews. To achieve the objective of the present survey, interview protocol was developed based on the following questions:

1) What are strengths and opportunities of using ICT in school smartization process?

2) What are weaknesses and threats of using ICT in school smartization process?

The encoding process and analysis of the qualitative data collected through interviews are presented in Table 1. In this process, items were classified into certain groups based on definitions, instances, and rule of encoding. Concurrent reliability method was adopted to ensure the reliability of the research tools. The researchers encoded and analyzed data concurrently and compared the results. The 
findings had sufficient validity. Moreover, attitude of the researchers did not directly interfere with the interpretation of the findings.

Table 1. The Process of Encoding Interview-based Derived Categories

\begin{tabular}{|c|c|c|c|}
\hline Item & Definition & Instance & Encoding Rules \\
\hline \multirow{6}{*}{$\begin{array}{l}\text { Weakness of the } \\
\text { policy Strategies of } \\
\text { ICT development }\end{array}$} & $\begin{array}{l}\text {-Lack of unity and } \\
\text { consistency in policy }\end{array}$ & \multirow{6}{*}{$\begin{array}{l}\text { Lack of uniformity } \\
\text { policy and consistent } \\
\text { Change of policies as } \\
\text { officials are } \\
\text { discharged (no. 7) }\end{array}$} & Proper policy making \\
\hline & $\begin{array}{l}\text { - Modification of } \\
\text { policies as officials } \\
\text { change }\end{array}$ & & \multirow{5}{*}{$\begin{array}{l}\text { Addressing the } \\
\text { majority of the } \\
\text { problems }\end{array}$} \\
\hline & $\begin{array}{l}\text {-Lack of theoretical } \\
\text { principles in } \\
\text { supporting the } \\
\text { measures }\end{array}$ & & \\
\hline & $\begin{array}{l}\text {-Lack of benefiting } \\
\text { from the development } \\
\text { model }\end{array}$ & & \\
\hline & $\begin{array}{l}\text {-Problems raised from } \\
\text { negative approach of } \\
\text { authorities and } \\
\text { parents to ICT because } \\
\text { of low levels of } \\
\text { knowledge }\end{array}$ & & \\
\hline & $\begin{array}{l}\text {-Public cultural } \\
\text { problems when faced } \\
\text { with ICT }\end{array}$ & & \\
\hline \multirow{10}{*}{$\begin{array}{l}\text { Disruption of } \\
\text { structural factors } \\
\text { and technological } \\
\text { infrastructure }\end{array}$} & $\begin{array}{l}\text {-Hardware problems } \\
\text { such as supplying side } \\
\text { and required tools }\end{array}$ & $\begin{array}{l}\text { Lack of attention of } \\
\text { authorities to } \\
\text { impropriety of } \\
\text { physical setting } \\
\text { required for enforcing } \\
\text { school smartization } \\
\text { plan (no. 4) }\end{array}$ & $\begin{array}{l}\text { Major challenge is } \\
\text { infrastructure that } \\
\text { mismatches with the } \\
\text { previous content. }\end{array}$ \\
\hline & $\begin{array}{l}\text {-Problems with } \\
\text { communication } \\
\text { networks and internet } \\
\text { speed limitations }\end{array}$ & \multirow{9}{*}{$\begin{array}{l}\text { Low governmental } \\
\text { support of } \\
\text { non-governmental } \\
\text { schools (interview } \\
\text { with person no. 8) }\end{array}$} & \multirow{9}{*}{$\begin{array}{l}\text { Serious and } \\
\text { comprehensive } \\
\text { attention to a system } \\
\text { in which all elements } \\
\text { are interacting. }\end{array}$} \\
\hline & $\begin{array}{l}\text {-Problems of } \\
\text { school-specific } \\
\text { security policies }\end{array}$ & & \\
\hline & $\begin{array}{l}- \text { Problems of } \\
\text { installing low-quality } \\
\text { antivirus applications }\end{array}$ & & \\
\hline & $\begin{array}{l}\text {-Executive problems in } \\
\text { enforcement of plans }\end{array}$ & & \\
\hline & $\begin{array}{l}\text {-Lack of systematic } \\
\text { associations between } \\
\text { sectors }\end{array}$ & & \\
\hline & $\begin{array}{l}\text { - Mismatch between } \\
\text { organizational } \\
\text { structure and } \\
\text { requirements for } \\
\text { developing ICT } \\
\text { technology }\end{array}$ & & \\
\hline & -Focus of education & & \\
\hline & $\begin{array}{l}\text { - Mismatch of the } \\
\text { dominant trend of } \\
\text { learning-training } \\
\text { process and } \\
\text { evaluation system } \\
\text { with ICT strategies }\end{array}$ & & \\
\hline & $\begin{array}{l}\text {-Legal and actual } \\
\text { problems }\end{array}$ & & \\
\hline \multirow{3}{*}{$\begin{array}{l}\text { Insufficient Expert } \\
\text { Labor Force }\end{array}$} & $\begin{array}{l}\text {-Lack of expert and } \\
\text { skilled labor force in } \\
\text { ICT }\end{array}$ & \multirow{3}{*}{$\begin{array}{l}\text {-Lack of sufficient } \\
\text { fluency of teachers } \\
\text { and students in } \\
\text { English (interviewee } \\
\text { no.3) }\end{array}$} & \multirow{3}{*}{$\begin{array}{l}\text { Expressing subgroup } \\
\text { aspects of future } \\
\text { challenges }\end{array}$} \\
\hline & $\begin{array}{l}\text {-Lack of courses } \\
\text { regarding use of } \\
\text { information } \\
\text { technology in } \\
\text { Tarbiat-Moalem } \\
\text { universities }\end{array}$ & & \\
\hline & $\begin{array}{l}\text {-Low quality of } \\
\text { in-service courses for } \\
\text { teachers for teaching } \\
\text { this technology in } \\
\text { classrooms }\end{array}$ & & \\
\hline
\end{tabular}

In qualitative studies, focus group method is used to understand people's perception of a distinctive subject. In this method, experts, their ideas, and comments are regarded as core of discussion. Then, through group interviews, participants review their own comments. Thus, the recent method is a qualitative study through which researchers could clarify the common approach of people about the studied phenomenon. In cases in which people with different characteristics are studied, multiple focus groups are selected based on existing characteristics, and each group is separately interviewed. Group members should be selected in such a way that each participant possesses a range of intended experiences. Selection of relatively homogenous people (6 to 12 people) allows to collect a vast range of participants' comments (15). Criterionbased targeted sampling requires selection of those items that constitute a significant criterion. In this method, characteristics of a sample or intended items are determined based on a number of criteria. Then, those items that meet the criteria are selected (16). Thematic or subjective analysis is a deductive analysis in which researchers obtain an analytical typology through data classification and data modeling. In other words, a thematic analysis is premised on encoding and analysis of data to understand its implications. This type of data initially seeks data modeling. When modeling is done, thematic analysis should be conducted. In other words, theme results from data (17). Finally, using SWOT model, the strategies for responding to the primary question of the present survey were developed. The method for using this environmental analysis model in strategic planning includes the following steps:

1) Developing a list of strengths, weaknesses, opportunities, and threats in certain tables

2) Comparing internal strengths with environmental opportunities and developing SO strategies

3) Comparing internal threats with environmental opportunities and developing WO strategies

4) Comparing internal strengths with external threats and developing ST strategies

5) Comparing internal weaknesses with external threats and offering WT strategies (18).

Weaknesses and strengths could be defined based on internal environment of smart schools system and opportunities and threats based on external environment of smart schools system. The strategies obtained based on strategic analyses of the present study were offensive, competitive, conservative, and defensive strategies and included in SWOT matrix.

All the interviewees provided a written consent, and they had the right to participate in relevant interviews. In addition, they were assured that their information would remain confidential. Moreover, they were assured that 
their information would be published anonymously in accordance with ethical considerations.

\section{Results}

The first measure of thematic analysis was analysis of interviews data. The objective was to answer the following question: What are strengths (internal) and opportunities (external) of using ICT in process of smartization of schools? The term organizational strength refers to resources, skills, abilities, and advantages concerning organizational requirements. An organization aims to satisfy organizational strength (3). In smart schools, strengths refer to software and hardware means, computer science, and expertise in dealing with technology, fluency in English, ability to create electronic content, use of compute for different educational fields such as representation of content and doing homework. In environments outside smart schools, using ICT in education could create potential opportunities. In contrast, a set of strengths and opportunities, which were classified, summarized, and reported based on interview documents, could be considered.

\subsection{Strengths and Opportunities of Using ICT in School Smarti- zation Process}

By reviewing and analyzing the experts' comments, it can be suggested that smart schools transfer a set of factors to their environment (mostly to students), which could be regarded as a key variable. Based on previous interviews, main codes were extracted from the interview texts and their primary themes are as follows:

Learner activity: because these schools are characterized by paying attention to the active role of students in learning and because individual differences of learners are considered within education process, they contribute to development of positive characteristics among learners. Based on psychological theories of cognitivists (eg, Piaget and Vygotsky) and because students are active and change through time, they experience a deep and meaningful learning. Learning becomes a joyful experience for them and imposes indirect educational effects on them. One of the interviewees stated:

"In these schools, it is attempted to address problems of learners in educational, physical, and psychological aspects. Disciplinary issues are less frequently observed in smart schools. With regards to disciplinary affairs, these schools are equipped with smart attendance system and closed circuit camera in their classrooms, halls, and laboratories. In the case of absence of a student, his/her parents are notified through SMS and this adds to the discipline of the students." (Interviewee No. 5)
Improving students' personality: emphasis on and attention to the active role of students in a learning center could be one of the proper opportunities of these schools. Because students and teachers' role have changed in these schools as teachers play a facilitating role and students should involve in the learning process, one of the major objectives of this educational system is personality improvement and educational aspect of a person. This significant issue is more clearly followed in the process of establishing these schools. One of the interviewees stated:

"One of the most significant opportunities before learners in smart schools is improving sense of selfconfidence and trust in oneself. In these schools, disciplinary issues are less frequent compared to typical schools. In smart schools, a teacher could adopt a wide range of methods for training. In addition, these schools add to creativity of leaners and open new paths for them. These schools contribute to internalization of information and data in a learner." (interviewee No. 3)

\subsection{Interactive Learning in Educational Settings}

Concurrent involvement of parents, teachers, and students in the learning process could add to quality of learning and creativity of students. Encouragement and positive feedback by teachers and parents could highly motivate the student. In this regard, one of the interviewees stated, "There are bilateral and multilateral associations between these factors and role of a student changes from a passive learner to an active one. School acts like a real training setting and learning becomes meaningful. In addition, the knowledge levels of involved parties (parent's knowledge of the child and administrator's knowledge of the teacher) acts in a monitoring manner. A person plays a more significant role in the learning process."

\subsection{Developing Educational Quality}

As one of the interviewees (No. 5) stated, one of the opportunities for using ICT in smartization of schools is as follows:

"Schools are basis of a society. For developing a society, technological tools and facilities as well as economic, cultural, and educational infrastructures should be available so that quality of education could be enhanced." (interviewee No. 5) (Figure 1).

\subsection{Weaknesses and Threats of Using ICT in School Smartization Process}

High rates of variation and slow changes of educational systems in fundamental infrastructures could act as serious threats against precise implementation of school smartization process. A part of encoding process is aimed 


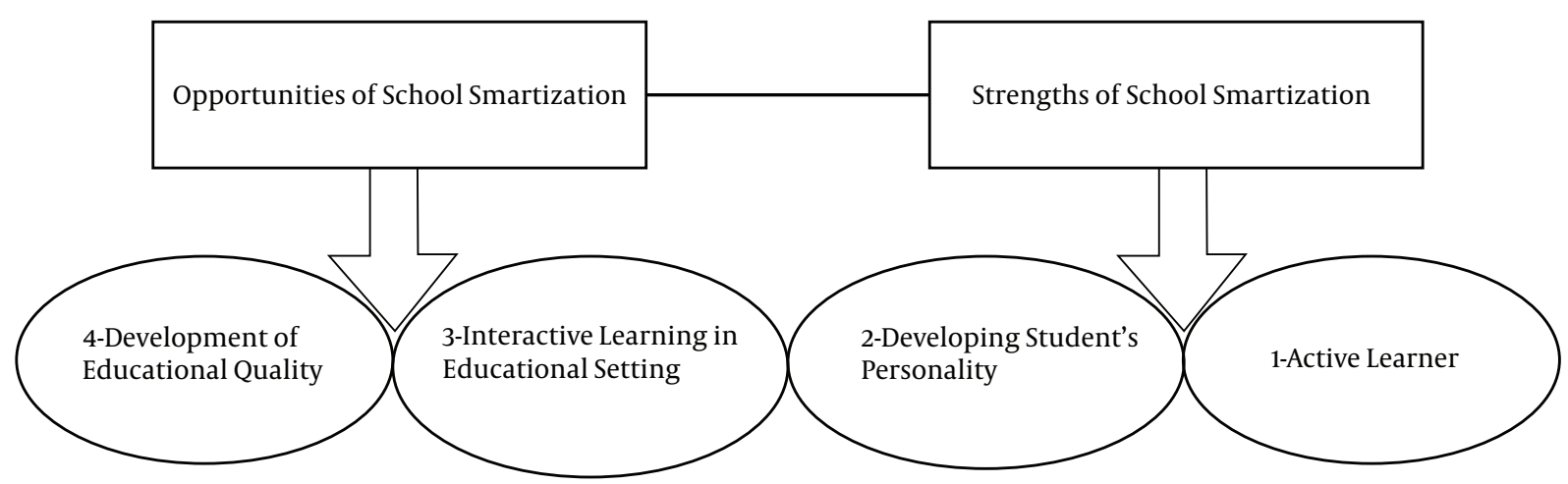

Figure 1. Scheme of Strengths and Opportunities of School Smartization [Research Findings]

at addressing the following question: What are strengths and threats of using ICT process in school smartization process?

Insufficiency of expert labor force: without presence of teachers with sufficient skills in dealing with abilities of ICT, one could not use this instrument in educating students or administrating schools. One of the barriers of slow-performing system is the lack of familiarity and expertise of labor force (ie, teachers). Most university lecturers do not benefit from sufficient practical courses and communicate content in a theoretical manner. When they face equipment and tools for practical use, they lack creativity and knowledge in using them. In addition, retraining and in-service courses held for teachers lack sufficient effectiveness and efficiency (19). Based on rate of changes in the world and in the field of educating teachers, teachers should have knowledge of latest tools, information, and ideas concerning their distinctive subject of study. In such schools, this lack of up-to-date knowledge of teachers in proper and effective use of these technological means prevents them from realization of intended objectives. One of the interviewees stated, "Using this tool requires sufficient and up-to-date knowledge of software information. Most of our colleagues are comfortable with the traditional method and do not care to use these applications and methods or they are not sufficiently fluent in English." (Interviewee No. 6)

Lack of skilled and efficient labor force in using ITbased methods in planning and educating learners, teachers' lack of expertise in operationalization of these methods, and lack of fluency in English are major problems against smartization of these schools.

Incorrect culture in use of ict tools: the majority of factors that could be mentioned as strengths of this system may contribute to entropy and cause fall of the system. This is implied by one of the interviewees:
"There is no such thing as threat. In other words, when requirements of an organization are not satisfied or are absent, they act as threats against the organization. For instance, in a smart school, the presence of professional labor force is required and if there is no such a force, it is regarded as a source of threat." (interviewee No. 4)

In addition, one of the interviewees stated:

"When a student is using a computer at home or school, he/she may do immoral works such as visiting immoral websites." (interviewee No. 6)

Considering threats against smart schools, participants 1, 4, and 6 stated that when using a computer at home or school, a student might do non-educational activities such as logging on immoral websites.

Weakness in policymaking and ICT Strategies: Making personal decisions, acting subjectively and the presence of ambiguous regulations could challenge establishment of this system and lower the rate of implementation of the system. It could act as a serious threat against the whole system as one of the interviewees suggested:

"Interference of education organization in registration of students in smart schools by periodization of registration of teachers and forwarding recommendation letters to such schools to make them register more students than they can manage (ie, more than 15 students per classroom) show that none of our schools has the essential conditions." (interviewee No.1)

To identify the major challenges against smartization of schools, a semi-structured interview with experts was done. After analyzing research data, 4 primary categories were identified. These categories were introduced within a thematic model called challenges and opportunities of school smartization from experts' viewpoint. The categories were described based on some interviews. Lack of strong theoretical principles for supporting these measures and benefiting from development model, problems 
resulting from the negative attitude of authorities and parents regarding ICT due to unfamiliarity with this technology, and lack of comparative studies were among major barriers against development of strategies in this field. One of the interviewees suggested:

"Our problem results from misperception of this new but effective system and this is because of lack of comparative studies in this field. I believe that the gap could be filled by trying more and drawing upon strong scientific evidence." (interviewee No. 5)

By making a correct policy, developing proper cultures for using this system, highlighting significance and advantages of this method (being premised on learning condition and orientation around students), conducting comparative studies and using this system in different societies, one could highlight the effects of this system and encourage students, parents, and teachers to adopt the system.

Mismatch between structural factors and technological infrastructure: IT infrastructure is among requirements of smartization process. There are new technologies, which teachers could use as means of e-learning such as the internet. The issue of educational equipment and modern technologies, especially its use in education process, is one of the most significant concerns of each institute or training unit. These equipment should be sufficient and satisfy relevant standard. In addition, because of their need for maintenance and support, these tools should be properly used. Lack of use and inaccessibility of these items are among major problems against school smartization. Hardware-related problems such as website development and maintenance in schools, connectivity problems, and internet speed limitation in these schools, problems concerning definite security policies in a school, lack of physical space required for implementation of school smartization process as well as problems of installing, operating, and updating applications delay enforcement of smart schools plan. One of the interviewees stated:

"Low access to up-to-date and proper apps in the school have always been challenging. For instance, low quality and heavy antivirus apps installed on school computers limit their rate of speed so that users are not willing to use the systems frequently." (Interviewee No. 3)

Among other issued raised among administrators regarding infrastructure and equipment needed, one could point to lack of sufficient space and equipment in such settings. One of interviewees stated:

"The school needs to assign equal space and facilities to all students. This is while in this school, there is not sufficient space for every student and they do not access presumed facilities. We are enforcing the plan with the least facilities." (interviewee No.1)
Therefore, for effective use of information technology in educational development, improvement of common approaches, revision of educational policies, reorganization of content, optimization of human resources, design of effective plans, and evolution of cultural and structural criteria for proper use of modern technologies should be considered. Lack of integrated policy and consistent change in policies or officials, low governmental support of these schools, lack of familiarity, and motivation of teachers employed in these schools are among problems, which challenge any progress in this area. One of the interviewees stated:

"Negligence of administrators and authorities of smart schools in developing a culture of using modern technologies in schools and ignorance of the necessity of teachers' positive approach to use this technology by training them in certain courses and conferences as well as insufficient support of government of these schools should be addressed." (interviewee No. 8)

As one could observe, in addressing and identifying key items in the area of technological infrastructure (software and hardness), some challenges against smartization of these schools were found. Evidently, the process of implementation of smartization factors in schools and increase of efficiency and performance of this system requires a serious, scientific, and realistic approach and sufficient knowledge of weaknesses and strengths of the system. In this case, existing barriers could be removed (Figure 2).

\subsection{Strategies of Using ICT in School Smartization Process}

To develop strategies and answer the following question: Which strategies could be suggested for use of ICT in school smartization process?, several attempts have been made, which are as follow: identifying weaknesses and strengths of school smartization, determining opportunities and threats of using information technology and its subfields, explaining factors affecting the system (realistic knowledge of financial, human and physical means, barriers against using them and efficient methods) in a way that strengths and opportunities are used in the best possible manner and that one could find solutions for addressing threats.

The items of analysis of interviews suggested that there are multiple influential factors based on which one could increase effectiveness and success of the system (Table 2).

Based on extracted strategies, interactive learning setting is used for activation of learners. Moreover, those in charge of smartization process should take steps in developing personality of students by improving quality of educational technology. Managers, policymakers and educational planners should make proper policies and offer 


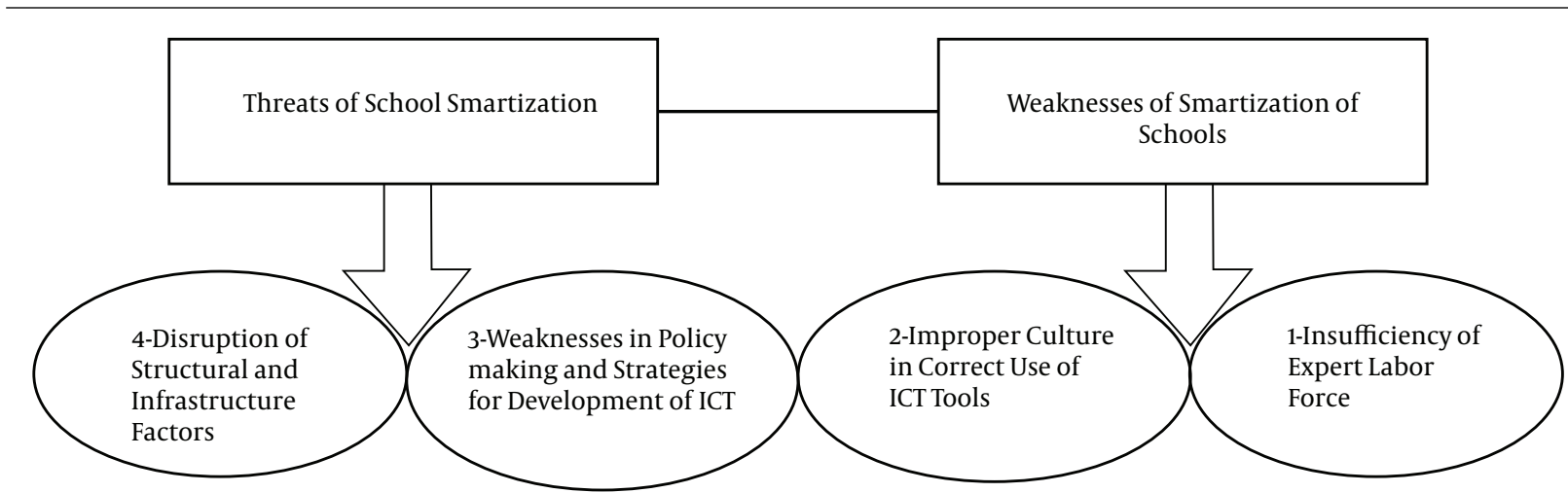

Figure 2. Schematic Presentation of Weaknesses and Challenges of School Smartization

Table 2. Matrix of Strategic Analysis of School Smartization Through SWOT Model

\begin{tabular}{|c|c|c|}
\hline \multirow[t]{2}{*}{ Internal factors } & \multicolumn{2}{|c|}{ External Factors } \\
\hline & Opportunities (0) & Threats (T) \\
\hline & $\begin{array}{l}\text { 3- Interactive learning in } \\
\text { educational settings }\end{array}$ & 2-Weakness in policymaking \\
\hline & $\begin{array}{l}\text { 4-Development of educational } \\
\text { quality }\end{array}$ & $\begin{array}{l}\text { 4- Disruption of structural } \\
\text { factors and technological } \\
\text { infrastructure }\end{array}$ \\
\hline Strengths $(\mathbf{S})$ & Offensive Strategy (SO) & Conservative Strategy (ST) \\
\hline 1-Active learner & $\begin{array}{l}\text { 1- Use of interactive learning } \\
\text { settings to allow learners to act }\end{array}$ & $\begin{array}{l}\text { 1- Modification of weaknesses of } \\
\text { policymaking and ICT } \\
\text { development strategies for } \\
\text { activation of learners }\end{array}$ \\
\hline $\begin{array}{l}\text { 2- Developing personality of } \\
\text { students }\end{array}$ & $\begin{array}{l}\text { 2-Attempt to develop } \\
\text { personality of student through } \\
\text { educational quality }\end{array}$ & $\begin{array}{l}\text { 2-Addressing structural and } \\
\text { infrastructure disruptions } \\
\text { based on personality } \\
\text { development objectives of } \\
\text { learners }\end{array}$ \\
\hline Weaknesses (W) & Competitive Strategy (WO) & Defensive Strategy (WT) \\
\hline $\begin{array}{l}\text { 1-Insufficiency of expert labor } \\
\text { force }\end{array}$ & $\begin{array}{l}\text { 1-Employment and enabling } \\
\text { human resources to activate } \\
\text { learners }\end{array}$ & $\begin{array}{l}\text { 1- Reduction of weakness of } \\
\text { policymaking in development } \\
\text { of expert labor force }\end{array}$ \\
\hline $\begin{array}{l}\text { 2-Improper culture of using } \\
\text { ICT tools }\end{array}$ & $\begin{array}{l}\text { 2-Developing educational } \\
\text { quality through culture of } \\
\text { effective use of ICT }\end{array}$ & $\begin{array}{l}\text { 1- Minimizing Improper ICT } \\
\text { utilization culture by } \\
\text { attempting to eliminate } \\
\text { structural and infrastructure } \\
\text { disruptions }\end{array}$ \\
\hline
\end{tabular}

strategic infrastructure for development of ICT to encourage students to perform more actively. Structural and infrastructure disruptions should be addressed to improve personality of learners. Hiring and empowering expert labor force so that they could encourage proactive learning should be followed by persons in charge and educational planners of schools. Quality of expert labor force should be developed through developing a culture of effective use of ICT. During interviews, some solutions were offered by interviewees, which could be reviewed by adopting extracted strategies. Other solution for smartization of schools was the experts. Among these suggestions, one could refer to periodical use of smart classrooms so that all teachers and students could use these means. For partially smartized schools, the following steps should be taken: assign- ing higher budget and special equipment for completing smartization process, assigning more authorities to manage the process, encouraging those teachers who use these technologies more frequently in classrooms than others, promoting a culture of proper use of technology, and developing a positive approach among families to technologies. Moreover, some of the solutions through which interviewers could smartize schools and realize the effective use of these schools were as follow: adding an IT course to the educational program of Tarbiat-Moalem universities and increasing skill of academic students in using this technology before they work as teachers, documenting and sharing experiences of pilot schools with other selected schools, passing specific solutions to encourage financial and nonmaterial participation of students in smartization of schools, gaining approval of facilitative guidelines for smartization of schools based on authorities of central education office to eliminate limiting principles, promoting culture of use, and informing parents of characteristics and advantages of using smart schools, developing managerial and executive structure of smart schools in central education office of Sanandaj, promoting and informing managers working in different ranks of central education office regarding requirements of smart schools, equipping schools with minimum means required for smartization, educating and improving teachers and students' skills, coordinating with Ministry of Communications and Information Technology to equip schools with high-speed internet.

\section{Discussion and Conclusions}

The strategies for using ICT in smartization of schools based on study of focus groups suggest that despite external challenges and internal weaknesses of school smartization, there are external opportunities and domestic 
strengths. By maximizing the strengths and opportunities and minimizing threats, and weaknesses of school smartization process, one could expect that typical and smart schools should attain their educational objectives and reach high levels of qualitative standards by using their potentials and latest technological means of education. The authorities and policymakers of education should acknowledge that merely labeling certain schools as smart will not suffice and they must make certain arrangements for these schools to satisfy the standards. They should train sufficient skilled and expert labor force, evaluate each school by its smartization process, and offer the results of their evaluation to educational managers and planners because these results could contribute to smartization of schools. Among significant items included in the suggested strategies, one could point to using interactive learning settings $(8,12,15)$, attempting to improve quality of education (8), adjusting weaknesses of policy making, and ICT development strategies (3), addressing structural and infrastructure disruptions $(3,10,12,15)$, recruiting and empowering expert labor force $(11,12)$ and promoting a culture for effective use of ICT (6). Based on deep analysis of the interviewees, the present study prioritized these elements.

In sum, one should note that if smart schools are developed based on items for smartization of conceptual model completely, some of the challenges of smartization could be prevented. Based on the findings of the present study, one could offer the following suggestions. The standards of school smartization process should be revised and complete enforcement of items in such schools should be assured. The more schools move towards the set standards, the less the problems and faults of using the smart school system. Educational policymakers and authorities should pay sufficient attention to problems of school smartization and not regard labeling certain schools smart as sufficient. The schools should be evaluated based on standards and progress of smartization process and results should be shared among schools administrators. Consequently, the administrators could find their position and rank in comparison with other schools. The authorities should score and devise special measures for smart schools to encourage administrators to smartize their schools. In this regard, education organization should make measures such as assigning more authorities to efficiently manage recruiting personnel and considering sufficient rights and advantages for teachers of smart schools to encourage them. At the beginning of each educational year, central education offices should notify administrators about rank of their smart schools and enable effective communication with other smart schools nationwide. The findings of the present study offer useful information for managers.
If an administrator intends to establish a smart school, he/she should know about required resources and equipment sufficiently. The present study offers a proper predictive tool for success of smart schools. Development of smart schools requires legal arrangements and permission of Ministry of Education.

\section{Acknowledgments}

We would like to acknowledge all participants who have contributed in the research interviews, anonymous reviewers for critical comments that greatly strengthened the manuscript, and the journal staff for regular review process.

\section{Footnotes}

Authors' Contribution: All authors contributed extensively to the presented paper that is described as follow: study concept and design: Ghobad Ramezani, Jamal Salimi; drafting of the manuscript: Ghobad Ramezani; data analysis and interpretation: Mohammad Asadi; critical revision of the manuscript for important intellectual content: Ghobad Ramezani, Jamal Salimi and Mohammad Asadi.

Conflict of Interest: No conflict of interest was observed in present study.

\section{References}

1. Rahimi M, Yadollahi S, editors. The anxiety of high school students and its relationship with the use of computers and personal computer ownership. Proceedings of the Fourth Conference on ELearning, University of Technology. 2011; Tehran. .

2. Fareghzadeh N, Kashi A. An Evaluation Of Virtual Education Methods And Tools To Improve Teaching Quality From the point of view of the Faculty Members of Islamic Azad University of Khodabandeh. Q J N Approach Educ Administ. 2014;4(5):121-15.

3. Mohajeran B, Ghaleei A, Hamzehrobati M. The Main Reasons for the Lack of Correct Formation of the Smart Schools and Presenting Solutions for Developing Them in Mazandaran province. Interdisciplinar J Virt Learn Med Sci. 2013;4(2):13-23.

4. Sánchez J, Salinas A, Harris J. Education with ICT in South Korea and Chile. Int J Educ Dev. 2011;31(2):126-48. doi: 10.1016/j.ijedudev.2010.03.003.

5. Mumtaz S. Using ICT in schools: a review of the literature on learning, teaching and software evaluation. University of Warwick, Centre for New Technologies Research in Education; 2000.

6. Abdolvahabi M, Mehralizade Y, Parsa A. The feasibility pitch of the smart schools. Educ Innov. 2011;11(43):81-112.

7. Alizad M. Smart schools quality in Tehran city. Tehran: Tehran University; 2012.

8. Zamani BE, Ghassabpur B, Jabal Ameli J. Evaluation of strengths, weaknesses, opportunities and threats of smart school. Rev Q J Educ Innov. 2010;9(36):79-100. 
9. Afzalkhany M, Ghods S. Evaluation of the deployment of intelligent secondary schools in the province of administrators and teachers. $J$ Inf Commun Technol Educ. 2011;2(1):23-40.

10. Yazdani N. The survey how use of ICT in smart schools in order to make learning opportunities by school teachers. Tehran: Allameh Tabatabaei University; 2011.

11. Jafari Hajati O. Evaluation of smart schools project in Tehran's high schools (case study: Absal high school). Tehran: Faculty of Psychology and Educational Sciences Tarbiat Moalem University; 2006.

12. Hedari M, Vazire M, Adli F. Evaluate and compare schools based on academic performance standards and critical thinking students with schools. Inf Commun Technol Educ. 2014;2(14):149-73.

13. Madhira S, Hamid QA, Prayaga SM, Kolloju S. Limited Wegener's granulomatosis with predominant otological presentation. Indian J Otolaryngol Head Neck Surg. 2011;63(Suppl 1):4-5. doi: 10.1007/s12070-0110167-0. [PubMed: 22754821].

14. Salimi L, Ghonoodi A. WCLTA 2011 The study of functional elements of management system in smart schools. Proc Soc Behav Sci. 2012;31:1404. doi:10.1016/j.sbspro.2011.12.031.

15. Mohamadpor A. Anti qualitative research method using two steps and practice in qualitative methodology. Tehran: Sociologists Publications; 2011

16. Zaree Nojini M. Identifying characteristics of electronic curriculum design in higher education in terms of curriculum and information technology specialists. Mashhad: University Ferdowsi of Mashhad; 2010.

17. Mohamadpour A, Boustani D, Alizadeh M. Qualitative assessment of welfare organizations and committees Help reduce poverty in female-headed households in Sari. Q J Soc Welfare. 2011;46.

18. Asgari M. Study problems and provide solutions for the development of smart schools in Western Azerbaijan Province. Western Azerbaijan Education Organization; 2009.

19. Hakimzadeh F, Abdolmaleki J. Proposal writing in qualitative and mixed method Researches. Tehran: Jameshenasan; 2011. 